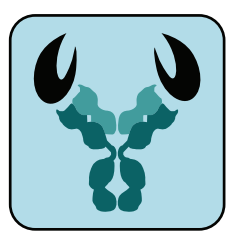

Journal of Experimental \& Clinical Cancer Research

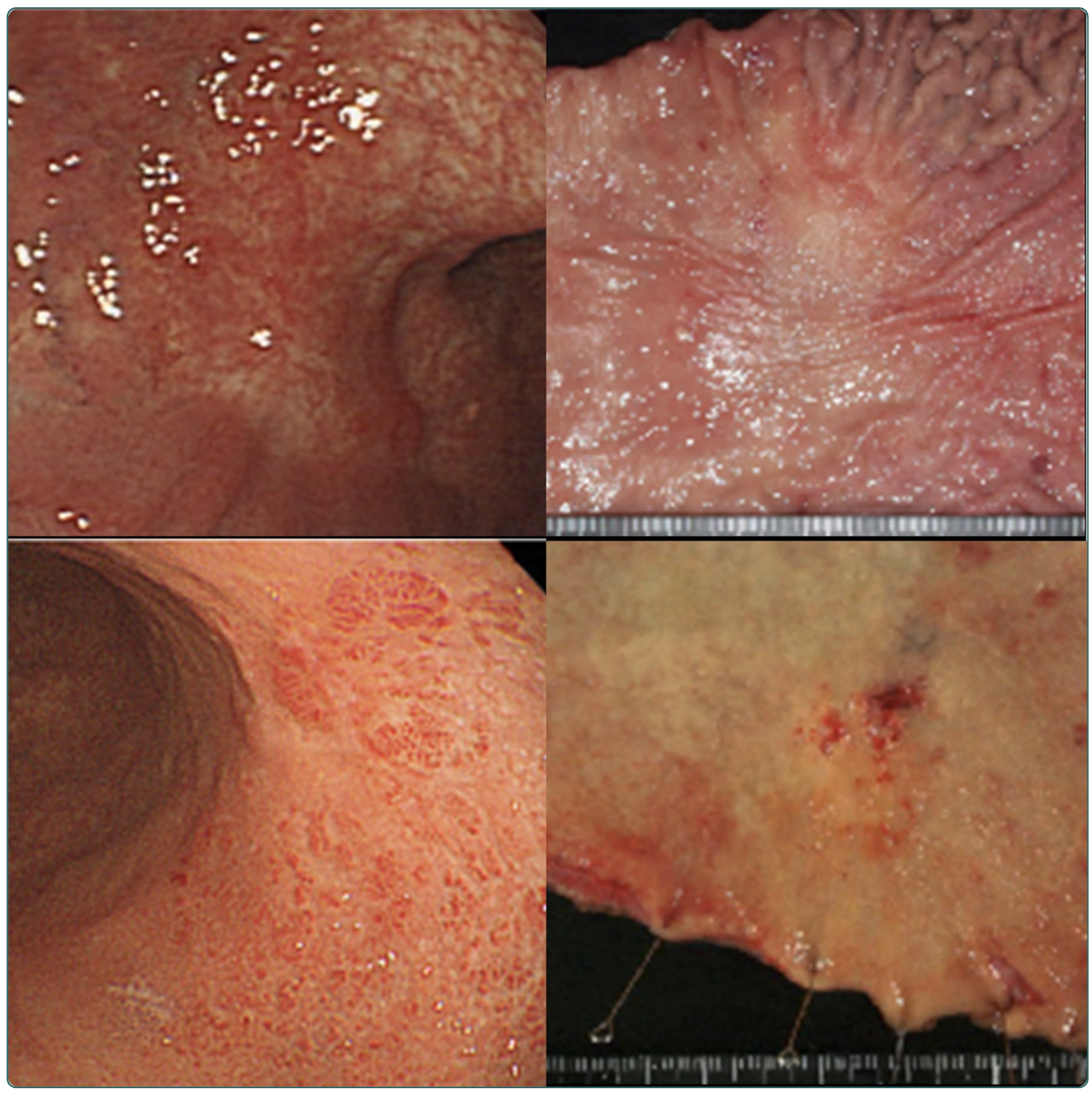

Clinicopathological characteristics and treatment strategies in early gastric cancer: a retrospective cohort study

Ito et al. 


\title{
Clinicopathological characteristics and treatment strategies in early gastric cancer: a retrospective cohort study
}

Hiroaki Ito ${ }^{1 *}$, Haruhiro Inoue ${ }^{1}$, Haruo Ikeda', Manabu Onimaru', Akira Yoshida', Toshihisa Hosoya ${ }^{1}, K^{1}$ Kosuke Sudo ${ }^{1}$, Nikolas Eleftheriadis ${ }^{1}$, Roberta Maselli ${ }^{1}$, Chiyo Maeda ${ }^{1}$, Yoko Wada ${ }^{1}$, Norimasa Sando ${ }^{1}$, Shigeharu Hamatani ${ }^{2}$ and Shin-ei Kudo ${ }^{1}$

\begin{abstract}
Background: Both endoscopic and surgical approaches are employed in the treatment of early gastric cancer (EGC). The aim of this study was to establish appropriate treatment strategies for early gastric cancer.

Methods: We retrospectively examined clinicopathological data of EGC patients who had undergone surgery.

Results: A total of 327 patients (204 males and 123 females, mean age 63.2 years) were eligible for inclusion in the study. The median follow-up period was 31 months. Of 161 mucosal (pT1a) tumors, 87 were mainly undifferentiated and 110 had an undifferentiated component. Four patients with pT1a tumors had lymph node metastases; all these tumors were signet-ring cell carcinomas and were macroscopic type 0-llc with ulceration, and only one of them had lymphatic invasion. Among patients with submucosal tumors, four of 43 patients with pT1b1 tumors and 37 of 123 patients with pT1b2 tumors had nodal metastases. Lymph node metastases were significantly higher in mixed undifferentiated type group than differentiated type group for both groups, pT1apT1b1 ( $p=0.0251)$ and pT1b2 ( $p=0.0430)$ subgroups. Only four of 45 patients with nodal metastases were diagnosed preoperatively by computed tomography (sensitivity $8.9 \%$, specificity $96.2 \%$ ). Nine patients with pT $1 \mathrm{~b}$ tumors had recurrence after surgery, and died. The sites of initial recurrence were liver, bone, peritoneum, distant nodes, and the surgical anastomosis.
\end{abstract}

Conclusions: The incidence of nodal metastases was approximately $5 \%$ in undifferentiated type mucosal (pT1a) tumors, and higher in submucosal (pT1b) tumors. The sensitivity of preoperative diagnosis of nodal metastases in EGC using computed tomography was relatively low in this study. Therefore at present surgery with adequate lymphadenectomy should be performed as curative treatment for undifferentiated type EGC.

Keywords: early gastric cancer, lymph node metastasis, endoscopic submucosal dissection

\section{Background}

Gastric cancer is the fourth leading cause of cancerrelated deaths worldwide [1]. Although advanced gastric cancer is often difficult to cure, early gastric cancer (EGC), which is generally recognized as a tumor with invasion confined to the mucosa or submucosa, is curable because of the low incidence of lymph node metastases [2]. The seventh edition of the International Union

\footnotetext{
* Correspondence: h.ito@med.showa-u.ac.jp

'Digestive Disease Center, Showa University Northern Yokohama Hospital,

35-1 Chigasakichuo, Tsuzuki-ku, Yokohama 224-8503, Japan

Full list of author information is available at the end of the article
}

Against Cancer TNM guidelines defines mucosal cancers as pT1a and submucosal cancers as pT1b [3]. The third English edition of the Japanese Classification of gastric carcinoma [4] submucosal tumors are further categorizes as submucosal tumors as pT1b1 (submucosal invasion $<0.5 \mathrm{~mm}$ ) or pT1b2 (submucosal invasion $\geq 0.5 \mathrm{~mm}$ ). Nodal metastases are rare in pT1a tumors [5,6], but occur in $2-9.8 \%$ of pT1b1 and $12-24.3 \%$ of pT1b2 tumors $[7,8]$. Surgery provides excellent cure rates for EGC [9], especially limited gastrectomy with [10-12] or without $[13,14]$ lymphadenectomy. Endoscopic treatment is a less invasive [15] alternative which

\section{Biomed Central}


is also used for the curative treatment of EGC [16], including endoscopic mucosal resection [17-20] and endoscopic submucosal dissection [15,21]. However, unsuitable use of endoscopic treatment for gastric cancer may result in local recurrence [22] and distant metastases [23] in cases which might otherwise have been curable, and should only be performed when there is an accurate diagnosis and prognosis.

The aim of this study was to investigate the optimal treatment strategy for EGC by evaluation of the clinicopathological characteristics. We focused particularly on histological type, because histological type is the only pathological factor which can be definitively diagnosed preoperatively.

\section{Methods}

\section{Patients}

All cases of solitary gastric adenocarcinoma which underwent curative surgery at the Digestive Disease Center, Showa University Northern Yokohama Hospital between April, 2001 and November, 2010 were retrospectively studied. The criteria for inclusion in the study were: (1) adenocarcinoma of the stomach histologically proven by endoscopic biopsy; (2) histologically solitary tumor; (3) no prior endoscopic resection, surgery, chemotherapy, or radiation therapy; (4) tumor invasion of the lamina propria or submucosa. Cases with synchronous or metachronous malignancy were excluded.

We examined relationships among histological type, tumor depth, nodal metastases, and prognosis. We also recorded the regional lymph node classification of the preoperative diagnosis. We generally performed preoperative screening for nodal metastases by computed tomography, followed by ultrasonography in cases with suspected nodal disease. Lymph nodes $\geq 1 \mathrm{~cm}$ in diameter on imaging were defined as metastatic nodes. We divided patients into four groups according to their pathological tumor types: (1) differentiated type including tumors mainly composed of well differentiated adenocarcinoma (tub1), moderately differentiated adenocarcinoma (tub2), or papillary adenocarcinoma (pap), and without poorly differentiated adenocarcinoma (por), signet-ring cell carcinoma (sig), or mucinous adenocarcinoma (muc) components; (2) mixed differentiated type including tumors mainly composed of tub1, tub2, or pap, and with por, sig, or muc components; (3) mixed undifferentiated type including tumors mainly composed of por, sig, or muc, and with tub1, tub2, or pap components; (4) undifferentiated type including tumors mainly composed of por, sig, or muc, and without tub1, tub2, or pap components. Disease was staged using the seventh edition of the International Union Against Cancer TNM guidelines [3].
All patient data were approved for use by the institutional review board of Showa University Northern Yokohama Hospital. Research reported in this paper was in compliance with the Helsinki Declaration.

\section{Statistical analysis}

Fisher's exact test was used to study relationships between nodal metastases and clinicopathological findings, and logistic regression analysis was applied to determine correlations between histological groups and nodal metastases. P-values less than 0.05 were considered to indicate statistical significance. Statistical analysis was performed using JMP Statistical Discovery 9.0.2 software (SAS Institute, Cary, USA).

\section{Results}

A total of 327 patients were eligible for inclusion in the study, including 204 males and 123 females, with a mean age of 63.2 years (range $31-89$ years). The median follow-up period was 31 months.

The clinicopathological characteristics of patients are shown in Table 1.

Relationships between clinicopathological characteristics and nodal metastases are shown in Table 2. The only characteristic significantly associated with nodal metastases was lymphatic invasion in pT1b2 tumors.

We combined pT1a (m) and pT1b1 (sm1) tumors into one group because the incidence of nodal metastases was under $10 \%$ in both, and compared relationships between histological types and nodal metastases in the pT1a-pT1b1 (m-sm1) and pT1b2 (sm2) groups (Table 3). A total of 45 out of 327 patients had nodal metastases, including 8 of the 204 patients in the pT1a-pT1b1 (m-sm1) group. Rates of nodal metastases were significantly higher in the mixed undifferentiated type group than the differentiated type group $(\mathrm{p}=0.0251)$.

Of 123 patients with pT1b2 tumors (sm2 group), 37 had nodal metastases. There was a significant association between depth of tumor invasion and nodal metastases in pT1b tumors. The incidence of nodal metastases was higher in the mixed undifferentiated type group than in the differentiated type group $(\mathrm{p}=$ 0.0430).

The pathological characteristics of patients in the pT1a-pT1b1 (m-sm1) group with nodal metastases are shown in Table 4. All four node-positive patients with pT1a tumors had ulceration (Figure 1). The smallest tumor size was $10 \mathrm{~mm}$ in diameter. One patient had non-perigastric nodal metastases along the common hepatic artery.

Only 4 of 45 patients with nodal metastases were diagnosed preoperatively (sensitivity $8.9 \%$, specificity 96.1\%). 
Table 1 Clinicopathological findings of patients with early gastric cancer $(n=327)$

\begin{tabular}{|c|c|}
\hline Variables & Number of subjects (\%) \\
\hline \multicolumn{2}{|l|}{ Sex } \\
\hline Male & $204(62.4)$ \\
\hline Female & $123(37.6)$ \\
\hline \multicolumn{2}{|l|}{ Gastrectomy } \\
\hline Distal & $211(64.5)$ \\
\hline Proximal & $34(10.4)$ \\
\hline Total & $81(24.8)$ \\
\hline Partial & $1(0.3)$ \\
\hline \multicolumn{2}{|l|}{ Surgical approarch } \\
\hline Laparoscopy & $236(72.2)$ \\
\hline Hand-assist & $27(8.3)$ \\
\hline Open laparotomy & 64 (19.6) \\
\hline \multicolumn{2}{|l|}{ Tumor depth * } \\
\hline pT1a (m) & $161(49.2)$ \\
\hline pT1b1 (sm1) & $43(13.1)$ \\
\hline pT1b2 (sm2) & $123(37.6)$ \\
\hline \multicolumn{2}{|c|}{ Lymph node metastasis $^{\dagger}$} \\
\hline pNO & $282(86.2)$ \\
\hline pN1 & $34(10.4)$ \\
\hline $\mathrm{pN} 2$ & $6(1.8)$ \\
\hline pN3 & $5(1.5)$ \\
\hline \multicolumn{2}{|l|}{ Distant metastasis $^{\dagger}$} \\
\hline MO & $327(100.0)$ \\
\hline M1 & $0(0)$ \\
\hline \multicolumn{2}{|l|}{ Main histologic type } \\
\hline Differentiated & $169(51.7)$ \\
\hline Undifferentiated & $158(48.3)$ \\
\hline \multicolumn{2}{|l|}{ Lymphatic invasion $^{+}$} \\
\hline LO & $246(75.2)$ \\
\hline L1-2 & $81(24.8)$ \\
\hline \multicolumn{2}{|l|}{ Venous invasion $^{\dagger}$} \\
\hline Vo & $279(85.3)$ \\
\hline V1-3 & $48(14.7)$ \\
\hline \multicolumn{2}{|l|}{ Stage $^{\dagger}$} \\
\hline IA & $282(86.2)$ \\
\hline $\mathrm{IB}$ & $34(10.4)$ \\
\hline$\|$ & $6(1.8)$ \\
\hline$\| \mathrm{A}$ & $5(1.5)$ \\
\hline
\end{tabular}

* According to the third English edition of the Japanese Classification of Gastric Carcinoma [4].

${ }^{+}$According to the seventh edition of the International Union Against Cancer TNM guidelines [3].

Nine patients had recurrence of cancer, and died. The initial site of recurrence was liver in three patients, bone in two, peritoneum in two, distant lymph nodes in one, and the surgical anastomosis in one (Table 5).

\section{Discussion}

The most important factor to consider when selecting treatment modalities for EGC is the presence of lymph node metastases. Although nodal metastases are rare in pT1a tumors, they have been reported to occur in 2$9.8 \%[7,8]$ of pT1b1 tumors and $12-24.3 \%[7,8]$ of pT1b2 tumors. Surgical treatment is generally undertaken for pT1b2 tumors. Detailed surveys have clarified the pathological characteristics of EGC with or without nodal metastases. Nodal metastases are uncommon in differentiated type mucosal tumors $[5,6,24]$ and in undifferentiated type mucosal tumors smaller than $20 \mathrm{~mm}$ in diameter without lymphatic invasion, venous invasion, or ulceration $[5,6,24]$.

Some limitations of this study should be considered. As the patients in this study were excluded from endoscopic treatment due to the possibility of nodal metastases, the incidence of nodal disease might be higher in this group than the overall incidence in a group which includes the patients who underwent endoscopic treatment. In this study, the incidence of nodal metastases was $2.5 \%$ in pT1a, $9.3 \%$ in pT1b1, and $30.1 \%$ in pT1b2 tumors. Although the incidence was under 10\% in both pT1a and pT1b1 tumors, it was relatively high in pT1b2 tumors compared with previous reports. Of the clinicopathological variables studied, only lymphatic invasion in pT1b2 tumors had a significant association with lymph node invasion. These results showed that the clinicopathological characteristics of pT1b1 tumors were more similar to those of p T1a tumors than those of pT1b2 tumors. We therefore combined pT1a and pT1b1 tumors in our analysis of relationships between histological types and nodal metastases. Mixed undifferentiated type tumors had a significantly higher incidence of nodal metastases than differentiated type tumors in both the pT1a-pT1b1 and the pT1b2 groups. Mixed histological type tumors have previously been reported to be a risk factor for nodal metastases [25], which is supported by our results showing that mixed undifferentiated type tumors are a risk factor for nodal metastases.

All four pT1a tumors and three of the pT1b1 tumors with nodal metastases in this study were signet-ring cell carcinomas with ulceration. The other pT1b1 tumor with nodal metastases was a differentiated type tumor without ulceration and without lymphatic or venous invasion. The $37 \mathrm{pT} 1 \mathrm{~b} 2$ tumors with nodal metastases had varying histological findings. It seemed that depth of tumor invasion was the most important prognostic factor in these tumors.

We performed surgery for curative treatment of EGC in cases which were thought to have a possibility of nodal metastases. However, pathological diagnosis of the surgical specimens shows that many of these cases were overtreated by their surgery [26]. Accurate preoperative diagnosis of the presence or absence of lymph node metastases would simplify treatment decisions. 
Table 2 Results of univariate analyses showing relationships between clinicopathological characteristics and lymph node metastases

\begin{tabular}{|c|c|c|c|c|c|c|}
\hline \multirow[t]{2}{*}{ Variables } & \multicolumn{2}{|c|}{$\begin{array}{l}\text { pT1a tumor } \\
(n=161)\end{array}$} & \multicolumn{2}{|c|}{$\begin{array}{l}\text { pT1b1 tumor } \\
(n=43)\end{array}$} & \multicolumn{2}{|c|}{$\begin{array}{l}\text { pT1b2 tumor } \\
(n=123)\end{array}$} \\
\hline & $\mathrm{pN}(+)$ & p-value & $\mathrm{pN}(+)$ & $\mathrm{p}$-value & $\mathrm{pN}(+)$ & p-value \\
\hline Total & $4 / 161(2.5 \%)$ & & $4 / 43(9.3 \%)$ & & $37 / 123(30.1 \%)$ & \\
\hline Sex & & 0.6269 & & 0.2802 & & 0.8309 \\
\hline Male & $3 / 88(3.4 \%)$ & & $4 / 28(14.3 \%)$ & & 26/88 (29.6\%) & \\
\hline Female & $1 / 73(1.4 \%)$ & & $0 / 15$ & & 11/35 (31.4\%) & \\
\hline Age & & 0.6332 & & 0.3449 & & 0.8432 \\
\hline$<65$ & 3/91 (3.3\%) & & $3 / 21(14.3 \%)$ & & 16/51 (31.4\%) & \\
\hline $65 \leq$ & $1 / 70(1.4 \%)$ & & $1 / 22(4.6 \%)$ & & 21/72 (29.2\%) & \\
\hline Main tumor site & & 0.1903 & & 0.2707 & & 0.1129 \\
\hline Upper & $0 / 19$ & & $0 / 3$ & & $3 / 21(14.3 \%)$ & \\
\hline Middle & $4 / 89(4.5 \%)$ & & $4 / 27(14.8 \%)$ & & $17 / 59(28.8 \%)$ & \\
\hline Lower & $0 / 53$ & & $0 / 13$ & & $17 / 43(39.5 \%)$ & \\
\hline Clinical macro type & & 0.5655 & & 0.5579 & & 0.4764 \\
\hline Depressed or excavated & $3 / 131(2.3 \%)$ & & $4 / 33(12.1 \%)$ & & 27/96 (28.1\%) & \\
\hline Flat or elevated & $1 / 30(3.3 \%)$ & & $0 / 10$ & & 10/27 (37.0\%) & \\
\hline Pathological macro type & & 1.0000 & & 1.0000 & & 0.4764 \\
\hline Depressed & 4/139 (2.9\%) & & $4 / 37(10.8 \%)$ & & $27 / 96(28.1 \%)$ & \\
\hline Flat or elevated & $0 / 22$ & & $0 / 6$ & & $10 / 27(37.0 \%)$ & \\
\hline Ulceration & & 0.1287 & & 0.3235 & & 0.4200 \\
\hline No & $0 / 72$ & & $1 / 23(4.4 \%)$ & & $21 / 77(27.3 \%)$ & \\
\hline Yes & $4 / 89(4.5 \%)$ & & $3 / 20(15.0 \%)$ & & $16 / 46(34.8 \%)$ & \\
\hline Main histologic type & & 0.1252 & & 0.4672 & & 0.8441 \\
\hline Differentiated & $0 / 74$ & & $2 / 29(6.9 \%)$ & & 19/66 (28.8\%) & \\
\hline Undifferentiated & $4 / 87(4.6 \%)$ & & $2 / 14(14.3 \%)$ & & 18/57 (31.6\%) & \\
\hline Pathological tumor size & & 1.0000 & & 1.0000 & & 0.0589 \\
\hline$\leq 20 \mathrm{~mm}$ & $1 / 60(1.7 \%)$ & & $0 / 7$ & & $4 / 28(14.3 \%)$ & \\
\hline $20 \mathrm{~mm}<$ & $3 / 101$ (2.5\%) & & $4 / 36(11.1 \%)$ & & $33 / 95(34.7 \%)$ & \\
\hline Pathological tumor size & & 0.3083 & & 1.0000 & & 0.1730 \\
\hline$\leq 30 \mathrm{~mm}$ & $1 / 96(1.0 \%)$ & & $2 / 21(9.5 \%)$ & & 13/55 (23.6\%) & \\
\hline $30 \mathrm{~mm}<$ & $3 / 65(4.6 \%)$ & & $2 / 22(9.1 \%)$ & & $24 / 68(35.3 \%)$ & \\
\hline Lymphatic invasion $^{\dagger}$ & & 0.0731 & & 0.5227 & & $<0.0001^{* *}$ \\
\hline LO & $3 / 158(1.9 \%)$ & & $3 / 36(8.3 \%)$ & & $4 / 52(7.7 \%)$ & \\
\hline L1-2 & $1 / 3(33.3 \%)$ & & $1 / 7(14.3 \%)$ & & $33 / 71(46.5 \%)$ & \\
\hline Venous invasion $^{+}$ & & 1.0000 & & 1.0000 & & 0.4200 \\
\hline V0 & $4 / 160(2.5 \%)$ & & 4/42 (9.5\%) & & $21 / 77(27.3 \%)$ & \\
\hline V1-3 & $0 / 1$ & & $0 / 1$ & & $16 / 46(34.8 \%)$ & \\
\hline
\end{tabular}

** $p<0.01$.

${ }^{+}$According to the seventh edition of the International Union Against Cancer TNM guidelines [3].

Table 3 Relationships among tumor depth, histological type, and lymph node metastases

\begin{tabular}{|c|c|c|c|c|c|}
\hline Tumor depth & Histologic type & $\mathrm{pN}(+)$ & Hazard ratio & $95 \%$ confidence interval & $p$-value \\
\hline \multirow[t]{4}{*}{$m-s m 1 \quad(n=204)$} & Differentiated & $1 / 72(1.4 \%)$ & 1.000 & & \\
\hline & Mixed differentiated & $1 / 31(3.2 \%)$ & 2.367 & $0.092-61.123$ & 0.5527 \\
\hline & Mixed undifferentiated & $3 / 22(13.6 \%)$ & 11.211 & $1.351-233.786$ & $0.0251^{*}$ \\
\hline & Undifferentiated & 3/79 (3.8\%) & 2.803 & $0.350-57.357$ & 0.3449 \\
\hline \multirow[t]{4}{*}{$\operatorname{sm} 2(n=123)$} & Differentiated & $11 / 41(26.8 \%)$ & 1.000 & & \\
\hline & Mixed differentiated & $8 / 25$ (32.0\%) & 1.283 & $0.423-3.808$ & 0.6539 \\
\hline & Mixed undifferentiated & 8/14 (57.1\%) & 3.636 & $1.042-13.478$ & $0.0430^{*}$ \\
\hline & Undifferentiated & $10 / 43(23.3 \%)$ & 0.826 & $0.303-2.230$ & 0.7054 \\
\hline
\end{tabular}


Table 4 Pathological characteristics of pT1a and pT1b1 tumors with lymph node metastases

\begin{tabular}{|c|c|c|c|c|c|c|c|c|c|c|}
\hline Case & $\begin{array}{l}\text { Tumor } \\
\text { depth * }\end{array}$ & $\begin{array}{l}\text { Macro } \\
\text { type }\end{array}$ & Ulceration & $\begin{array}{l}\text { Tumor size, } \\
\text { mm }\end{array}$ & $\begin{array}{l}\text { Histologic } \\
\text { type }\end{array}$ & $\mathrm{L}^{\dagger}$ & $\mathrm{v}^{+}$ & $\begin{array}{l}\text { Number of positive } \\
\text { node }\end{array}$ & $\begin{array}{l}\text { Follow-up time, } \\
\text { months }\end{array}$ & Status \\
\hline 1 & $m$ & $0-\| c$ & Yes & 10 & sig, tub2 & 0 & 0 & 1 & 97 & Alive \\
\hline 2 & $\mathrm{~m}$ & $0-\| c$ & Yes & 42 & $\begin{array}{l}\text { sig, tub2, } \\
\text { muc }\end{array}$ & 0 & 0 & 1 & 7 & Alive \\
\hline 3 & $\mathrm{~m}$ & $0-\| c$ & Yes & 60 & sig & 0 & 0 & 1 & 82 & Alive \\
\hline 4 & $\mathrm{~m}$ & 0-IIc & Yes & 100 & $\begin{array}{l}\text { sig, por, } \\
\text { tub1 }\end{array}$ & 1 & 0 & 1 & 25 & Alive \\
\hline 5 & $\mathrm{sm} 1$ & $0-\| c$ & No & 25 & tub1 & 0 & 0 & 1 & 76 & Alive \\
\hline 6 & $\mathrm{sm} 1$ & $0-\| c$ & Yes & 25 & tub2, por & 2 & 0 & 4 & 37 & Alive \\
\hline 7 & $\mathrm{sm} 1$ & $0-\| c$ & Yes & 31 & sig & 1 & 1 & 11 & 58 & $\begin{array}{l}\text { Deceased (bone } \\
\text { metastasis) }\end{array}$ \\
\hline 8 & $\mathrm{sm} 1$ & 0-IIc & Yes & 32 & por, sig & 1 & 0 & 1 & 20 & Alive \\
\hline
\end{tabular}

* According to the third English edition of the Japanese Classification of Gastric Carcinoma [4].

${ }^{\dagger}$ According to the seventh edition of the International Union Against Cancer TNM guidelines [3].

muc = mucinous adenocarcinoma; por = poorly differentiated adenocarcinoma; sig = signet-ring cell carcinoma; tub1 = well differentiated adenocarcinoma; tub2 $=$ moderately differentiated adenocarcinoma.

Preoperative and pathological tumor diagnoses may vary. The only part of the preoperative diagnosis which is almost definite is the histological type of the tumor. The accuracy of the preoperative diagnosis of depth of tumor invasion in mucosal tumors has been reported to be $80.2 \%$ [27]. Pathological findings after ESD show more detailed information and may indicate the need for additional treatment [28].

\section{Figure 1}

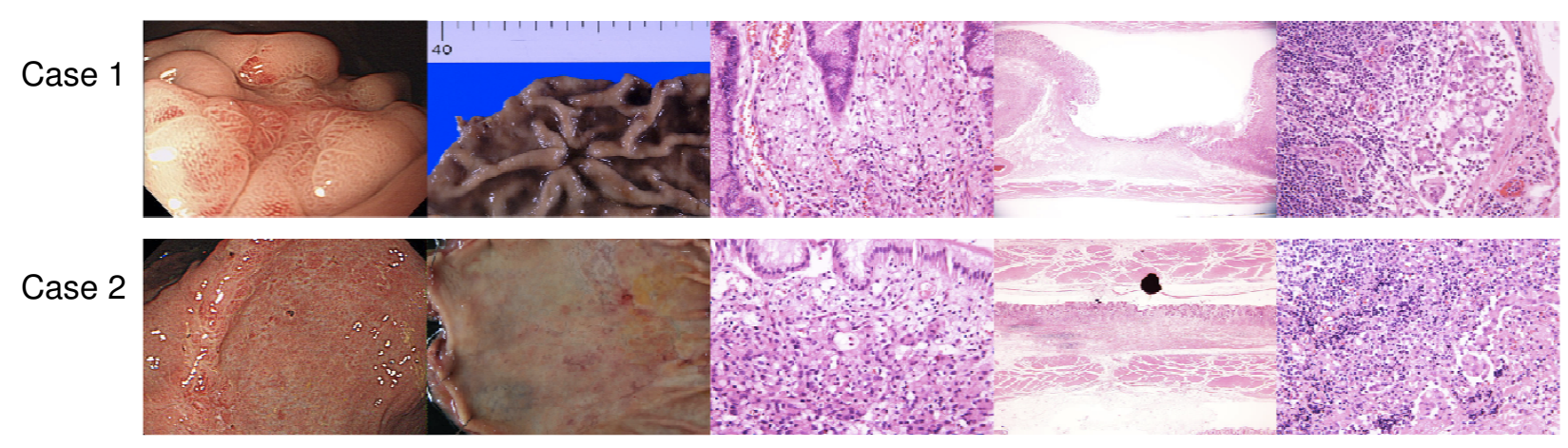

Case 3

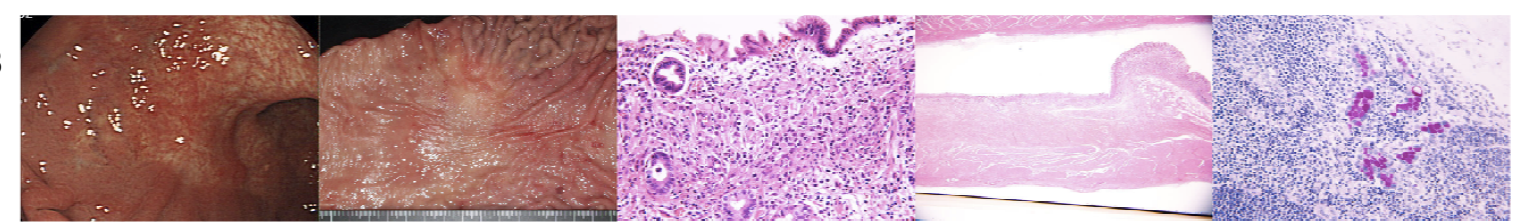

Case 4
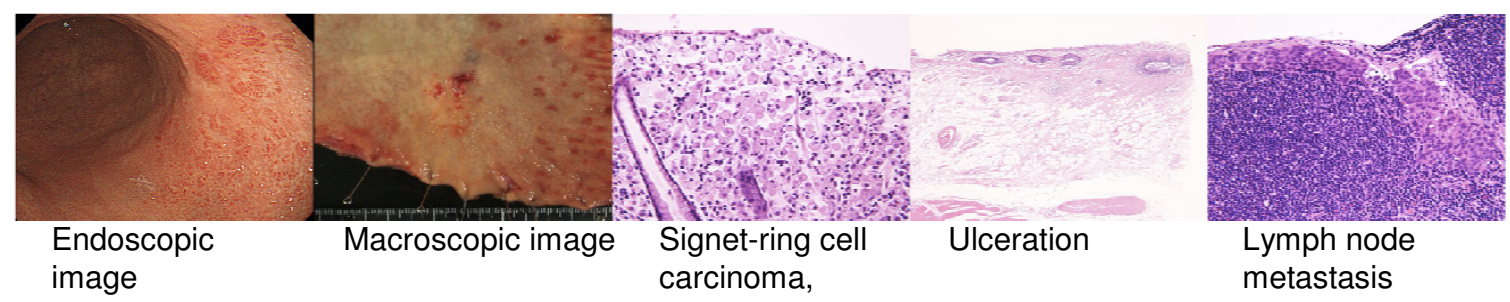

mucosal invasion

Figure 1 Endoscopic, macroscopic and pathological images of mucosal tumors with lymph node metastases. Four of 161 patients with mucosal tumors had nodal metastases. All of these patients had signet-ring cell carcinomas with ulceration. The smallest tumor was $10 \mathrm{~mm}$ in diameter (Case 1). One patient had non-perigastric nodal metastases along the common hepatic artery (Case 2). 
Table 5 Characteristics of cases with tumor recurrence $(n=9 / 327)$

\begin{tabular}{|c|c|c|c|c|c|c|c|c|c|c|c|}
\hline Case & $\begin{array}{l}\text { Extent of } \\
\text { gastrectomy }\end{array}$ & $\begin{array}{l}\text { Tumor } \\
\text { depth * }\end{array}$ & Ulceration & $\begin{array}{l}\text { Main histologic } \\
\text { type }\end{array}$ & $\underset{t}{\mathrm{~L}}$ & $\begin{array}{l}\text { V } \\
t\end{array}$ & $\underset{t}{\mathrm{pN}}$ & $\begin{array}{l}\text { Initial recurrence } \\
\text { site }\end{array}$ & $\begin{array}{l}\text { DFS, } \\
\text { months }\end{array}$ & $\begin{array}{l}\text { OS, } \\
\text { months }\end{array}$ & Status \\
\hline 1 & Distal & $\mathrm{sm} 1$ & Yes & sig & 1 & 0 & 3 & Bone & 53 & 58 & Deceased \\
\hline 2 & Distal & $\mathrm{sm} 2$ & Yes & por & 1 & 1 & 1 & Liver & 2 & 3 & Deceased \\
\hline 3 & Total & $\mathrm{sm} 2$ & Yes & por & 1 & 0 & 0 & Peritoneum & 7 & 8 & Deceased \\
\hline 4 & Total & $\mathrm{sm} 2$ & Yes & por & 1 & 1 & 1 & Liver & 12 & 20 & Deceased \\
\hline 5 & Distal & $\mathrm{sm} 2$ & Yes & tub2 & 1 & 1 & 1 & Lymph node & 12 & 44 & Deceased \\
\hline 6 & Distal & $\mathrm{sm} 2$ & Yes & por & 1 & 0 & 1 & Liver & 14 & 29 & Deceased \\
\hline 7 & Distal & $\operatorname{sm} 2$ & No & por & 1 & 0 & 3 & Bone & 19 & 21 & Deceased \\
\hline 8 & Distal & $\mathrm{sm} 2$ & No & por & 1 & 1 & 0 & Anastomosis & 23 & 65 & Deceased \\
\hline 9 & Total & $\mathrm{sm} 2$ & No & tub2 & 1 & 0 & 0 & Peritoneum & 41 & 44 & Deceased \\
\hline
\end{tabular}

* According to the third English edition of Japanese Classification of Gastric Carcinoma [4].

${ }^{\dagger}$ According to the seventh edition of TNM classification of the International Union Against Cancer [3].

por = poorly differentiated adenocarcinoma; sig = signet-ring cell carcinoma; tub2 = moderately differentiated adenocarcinoma; DFS = disease-free survival; OS = overall survival.

The accuracy of preoperative diagnosis of nodal metastases in EGC using computed tomography varies widely by methodology $[29,30]$. In this study, the accuracy of preoperative diagnosis was relatively low, and we did not know whether nodal metastases were present until we performed surgery with lymphadenectomy. We therefore selected treatment based mainly on the histological type of the tumor.

In general, we should currently perform surgery with adequate lymphadenectomy for EGC with an undifferentiated tumor type.

\section{Conclusions}

Both endoscopic and surgical approaches are employed in the treatment of EGC. The aim of this study was to establish appropriate strategies for the treatment of EGC. We retrospectively examined the clinicopathological data of EGC patients who had undergone surgery. A total of 327 patients were eligible for the study, with a median follow-up period of 31 months. Nodal metastases were found in 4 of 161 patients with pT1a tumors; these were all signet-ring cell carcinomas with Type 0IIc macroscopic appearance, and three of them did not have lymphatic or venous invasion. Nodal metastases were found in 4 of 43 patients with pT1b1 tumors and 37 of 123 patients with pT1b2 tumors. Lymph node metastases were significantly higher in mixed undifferentiated type group than differentiated type group for both groups, pT1a-pT1b1 $(\mathrm{p}=0.0251)$ and $\mathrm{pT} 1 \mathrm{~b} 2(\mathrm{p}=$ $0.0430)$ subgroups. The sensitivity of preoperative diagnosis of nodal metastases was $8.9 \%$ and the specificity was $96.1 \%$. Nine patients with pT1b tumors had recurrence after surgery, with the initial sites of recurrence being liver, bone, peritoneum, distant nodes, and the surgical anastomosis. As the accuracy of preoperative diagnosis of nodal metastases was relatively low, we should at present perform surgery with adequate lymphadenectomy for undifferentiated type EGC.

\section{Abbreviations}

DFS: disease-free survival; OS: overall survival; UICC: International Union Against Cancer

muc: mucinous adenocarcinoma; por: poorly differentiated adenocarcinoma; sig: signet-ring cell carcinoma; tub1: well differentiated adenocarcinoma; tub2: moderately differentiated adenocarcinoma

\section{Acknowledgements}

We are extremely grateful to all the patients. We would like to be most grateful to clinical staff, Dr Noriko Odaka, and Dr Hitoshi Satodate..

\section{Author details}

1Digestive Disease Center, Showa University Northern Yokohama Hospital, 35-1 Chigasakichuo, Tsuzuki-ku, Yokohama 224-8503, Japan. ${ }^{2}$ Department of Pathology, Showa University Northern Yokohama Hospital, 35-1 Chigasakichuo, Tsuzuki-ku, Yokohama 224-8503, Japan.

\section{Authors' contributions}

$\mathrm{HI}^{*}$ conceived and designed the study, collected clinical data, and performed the statistical analysis and interpretation of data. HI participated in the study design and performed interpretation of data. $\mathrm{HI}, \mathrm{MO}, \mathrm{AY}, \mathrm{TH}$, and KS collected clinical data. NE, RM, and NS participated in the study design and performed interpretation of data. CM and YW collected clinical data. NS participated in the study design and performed interpretation of data. SH delivered patients' pathologic data. SK participated in the study design and coordination. All authors read and approved the final manuscript.

\section{Competing interests}

The authors declare that they have no competing interests.

Received: 14 December 2011 Accepted: 29 December 2011 Published: 29 December 2011

\section{References}

1. Parkin DM, Bray F, Ferlay J, Pisani P: Global cancer statistics, 2002. CA Cancer J Clin 2005, 55(2):74-108.

2. Moreaux J, Bougaran J: Early gastric cancer. A 25-year surgical experience. Annals of surgery 1993, 217(4):347-355.

3. Sobin LH, Gospodarowicz MK, Wittekind C: TNM classification of malignant tumors. Oxford: Wiley-Blackwell; 72010.

4. Japanese classification of gastric carcinoma: 3rd English edition. Gastric Cancer 2011, 14(2):101-112. 
5. Gotoda T, Yanagisawa A, Sasako M, Ono H, Nakanishi Y, Shimoda T, Kato Y: Incidence of lymph node metastasis from early gastric cancer: estimation with a large number of cases at two large centers. Gastric Cancer 2000, 3(4):219-225.

6. Yamao T, Shirao K, Ono H, Kondo H, Saito D, Yamaguchi H, Sasako M, Sano T, Ochiai A, Yoshida S: Risk factors for lymph node metastasis from intramucosal gastric carcinoma. Cancer 1996, 77(4):602-606.

7. Kurihara N, Kubota T, Otani Y, Ohgami M, Kumai K, Sugiura H, Kitajima M: Lymph node metastasis of early gastric cancer with submucosal invasion. Br J Surg 1998, 85(6):835-839.

8. Gotoda T, Sasako M, Ono H, Katai H, Sano T, Shimoda T: Evaluation of the necessity for gastrectomy with lymph node dissection for patients with submucosal invasive gastric cancer. Br J Surg 2001, 88(3):444-449.

9. Popiela T, Kulig J, Kolodziejczyk P, Sierzega M: Long-term results of surgery for early gastric cancer. Br J Surg 2002, 89(8):1035-1042.

10. Seto $Y$, Nagawa H, Muto Y, Kaizaki S, Kitayama J, Muto T: Preliminary report on local resection with lymphadenectomy for early gastric cancer. $\mathrm{Br} J$ Surg 1999, 86(4):526-528

11. Seto Y, Yamaguchi H, Shimoyama S, Shimizu N, Aoki F, Kaminishi M: Results of local resection with regional lymphadenectomy for early gastric cancer. Am J Surg 2001, 182(5):498-501.

12. Shimoyama S, Seto $Y$, Yasuda H, Kaminishi M: Wider indications for the local resection of gastric cancer by adjacent lymphadenectomy. J Surg Oncol 2000, 75(3):157-164.

13. Kobayashi T, Kazui T, Kimura T: Surgical local resection for early gastric cancer. Surgical laparoscopy, endoscopy \& percutaneous techniques 2003, 13(5):299-303.

14. Ohgami M, Otani Y, Kumai K, Kubota T, Kim Yl, Kitajima M: Curative laparoscopic surgery for early gastric cancer: five years experience. World J Surg 1999, 23(2):187-192, discussion 192-183.

15. Kim HM, Kim HK, Lee SK, Cho JH, Pak KH, Hyung WJ, Noh SH, Kim CB, Lee YC, Song SY, et al: Multifocality in Early Gastric Cancer Does not Increase the Risk of Lymph Node Metastasis in a Single-Center Study. Ann Surg Oncol 2011.

16. Chung YS, Park DJ, Lee HJ, Kim SG, Jung HC, Song IS, Kim WH, Lee KU, Choe KJ, Yang HK: The role of surgery after incomplete endoscopic mucosal resection for early gastric cancer. Surgery today 2007, 37(2):114-117.

17. Inoue H, Takeshita K, Hori H, Muraoka Y, Yoneshima H, Endo M: Endoscopic mucosal resection with a cap-fitted panendoscope for esophagus, stomach, and colon mucosal lesions. Gastrointest Endosc 1993, 39(1):58-62.

18. Takizawa K, Oda I, Gotoda T, Yokoi C, Matsuda T, Saito Y, Saito D, Ono H: Routine coagulation of visible vessels may prevent delayed bleeding after endoscopic submucosal dissection-an analysis of risk factors. Endoscopy 2008, 40(3):179-183.

19. Itoi T, Kawai T, Sofuni A, Itokawa F, Tsuchiya T, Kurihara T, Kusano C, Saito Y, Gotoda T: Efficacy and safety of 1-step transnasal endoscopic nasobiliary drainage for the treatment of acute cholangitis in patients with previous endoscopic sphincterotomy (with videos). Gastrointest Endosc 2008, 68(1):84-90.

20. Inoue H, Tani M, Nagai K, Kawano T, Takeshita K, Endo M, Iwai T: Treatment of esophageal and gastric tumors. Endoscopy 1999, 31(1):47-55.

21. Ono $\mathrm{H}$ : Endoscopic submucosal dissection for early gastric cancer. Chinese journal of digestive diseases 2005, 6(3):119-121.

22. Youn JC, Youn YH, Kim TI, Park SW, Lee SJ, Song SY, Chung JB, Lee YC: Factors affecting long-term clinical outcomes of endoscopic mucosal resection of early gastric cancer. Hepatogastroenterology 2006, 53(70):643-647.

23. Jeong G, Lee JH, Yu MK, Moon W, Rhee PL, Paik SW, Rhee JC, Kim JJ: Nonsurgical management of microperforation induced by EMR of the stomach. Dig Liver Dis 2006, 38(8):605-608.

24. Hirasawa T, Gotoda T, Miyata S, Kato Y, Shimoda T, Taniguchi H, Fujisaki J, Sano T, Yamaguchi T: Incidence of lymph node metastasis and the feasibility of endoscopic resection for undifferentiated-type early gastric cancer. Gastric Cancer 2009, 12(3):148-152.

25. Hanaoka N, Tanabe S, Mikami T, Okayasu I, Saigenji K: Mixed-histologictype submucosal invasive gastric cancer as a risk factor for lymph node metastasis: feasibility of endoscopic submucosal dissection. Endoscopy 2009, 41(5):427-432.

26. O'Mahony S: Endoscopic mucosal resection for early gastric cancer. Gut 2001, 48(2):151-152.
27. Seto Y, Shimoyama S, Kitayama J, Mafune K, Kaminishi M, Aikou T, Arai K, Ohta K, Nashimoto A, Honda I, et al: Lymph node metastasis and preoperative diagnosis of depth of invasion in early gastric cancer. Gastric Cancer 2001, 4(1):34-38.

28. Nakamoto S, Sakai Y, Kasanuki J, Kondo F, Ooka Y, Kato K, Arai M, Suzuki T, Matsumura T, Bekku D, et al: Indications for the use of endoscopic mucosal resection for early gastric cancer in Japan: a comparative study with endoscopic submucosal dissection. Endoscopy 2009, 41(9):746-750.

29. Wang YP, Bennett C, Pan T: Endoscopic mucosal resection for early gastric cancer. Cochrane Database Syst Rev 2006, , 1: CD004276.

30. Cho JY, Kim YS, Jung IS, Ryu CB, Lee MS, Shim CS, Jin SY: Controversy concerning the cutoff value for depth of submucosal invasion after endoscopic mucosal resection of early gastric cancer. Endoscopy 2006, 38(4):429-430, author reply 430.

\section{doi:10.1186/1756-9966-30-117}

Cite this article as: Ito et al:: Clinicopathological characteristics and treatment strategies in early gastric cancer: a retrospective cohort study. Journal of Experimental \& Clinical Cancer Research 2011 30:117.

\section{Submit your next manuscript to BioMed Central and take full advantage of:}

- Convenient online submission

- Thorough peer review

- No space constraints or color figure charges

- Immediate publication on acceptance

- Inclusion in PubMed, CAS, Scopus and Google Scholar

- Research which is freely available for redistribution 